\title{
Evaluation of the Directly Observed Treatment Short Course Program for Tuberculosis in Health Care Centers of Karachi: A Cross Sectional Study Highlighting the Problems Encountered
}

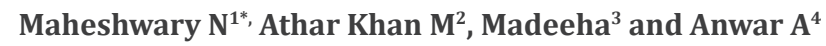 \\ ${ }^{1}$ Manager Medical Affairs \& Clinical Research, Hilton Pharma Pvt Ltd, Pakistan \\ ${ }^{2}$ Department of Community Medicine, Liaquat College of Medicine \& Dentistry, Karachi, Pakistan. \\ ${ }^{3}$ Medical Officer Hospital, Karachi, Pakistan \\ ${ }^{4}$ Sr. Lecturer, Altibri medical college, Karachi, Pakistan
}

\begin{abstract}
Received: 01 March, 2017; Accepted: 13 April, 2017; Published: 24 April, 2017
*Corresponding author: Neeta Maheshwary, Manager Medical Affairs \& Clinical Research, Hilton Pharma PVT Ltd, Beaumont Road, Pakistan, Tel: (021) 111-123-000; Cell No: 0092-3228247773; E-mail: drneeta@hiltonpharma.com
\end{abstract}

\begin{abstract}
Objective: To assess and highlight the areas in which problems are encountered by the health care providers during delivery of DOTS therapy and hence are halting the success of DOTS and propagating the disease.

Material \& Methods: This was a cross sectional study with convenient sampling conducted between April 2016 to Sept 2016 at Primary Health Care centers in Karachi. A total of 100 Health care providers were part of this study. Out of these 100 health care workers, 25 were excluded from the study due to the incomplete filling of the questionnaire. A questionnaire was filled by the workers in which Demographic, clinical and treatment outcome factors and social determinants of health were recorded for each patient. Doctors, Nurses and Health Workers working as part time at Primary Health Care centers of Karachi with experience of more than 06 months were included. Ethical considerations were followed and names of participants and care centers were kept confidential. The data was analyzed through SPSS version 17.0
\end{abstract}

Results: Among the 75 respondents male to female ratio was 1:1. Around $36(48 \%)$ were doctors, 18 (24\%) were nurses, 21 (28\%) were lady health workers. Their working experience was less than 1 year, 1 to 5 years, 6 to 10 years and more than 10 years in $17(22.7 \%), 32(42.7 \%)$, $13(17.3 \%)$ and $13(17.3 \%)$ respectively. The compliance of the patients was below average, average and good in 46(61.3\%), 22(29.3\%), 7(9.3\%) respectively. The overall TB DOT program was rated as Fair in 34(45\%), good in $33(44 \%)$ and very good in $8(11 \%)$

Conclusion: The major areas of constrain highlighted are patient compliance to treatment, access to health facilities, education about TB and its treatment and problems faced during field work and reporting. However, refining these parameters will lead to paramountimplementation of DOTS therapy and thus, can improve many folds and disease can drop reciprocally.

Keywords: Evaluation; Directly observed treatment short course program; Tuberculosis

\section{Introduction}

Tuberculosis (TB) is ranked second most common cause of death attributable to infectious disease. Globally 9.4 million incidents and 14 million prevalent cases occurred in 2010. It is a treatable and preventable disease [1].

Tuberculosis is a bacterial pathogen that causes infection of lungs primarily but can also disseminate to other organs. Most common presentation is productive cough, night sweats, fever and weight loss. Chest X-ray can be of diagnostic help but sputum culture is a gold standard for its diagnosis. Its treatment requires multi drug regimen and resistance is a common phenomenon, which makes multi-drug resistance TB a global threat [2].

The most important indicator of TB control program is treatment. Hence monitoring and evaluation of treatment outcomes of TB patients in regards to treatment outcomes is an integral part of the Directly Observed Treatment Short Course(DOTS) strategy [3].

The (DOTS) strategy, which aims at delivering drugs to the patient at daily basis under supervision of health care professionals, thereby enhancing treatment compliance, and improve TB cure rate.

The DOTS strategy for cure and control of tuberculosis was launched by the World Health Organization in 1995. The approachmainly focuses on delivering short course treatment regimens for a minimum of six months, but also takes into account tenets such as political commitment, good management practices, sputum smear microscopy for diagnosis, and the direct observation of doses to ensure adherence. Up until now DOTS 
remains the foundation of global efforts at tuberculosis control [4].

Among the global health interventions, DOTS is one of the most widely-executed and longest-running strategy in its field [5].

In implicating the DOTS therapy and for it to become a success and cure TB there are many factors that need to be taken into consideration including the knowledge and perception of health care providers and patients about TB and its fatal complications and the usage of DOTS in its treatment. A markedly reduced level of treatment failure, relapse and resistance have been noted after the implementation of DOTS therapy [6,7].

A health care provider delivers care to TB patients who are in need of health care services. It includes Clinicians and other staff, including those in primary care and TB centers, who have contact with TB patients on regular basis such as doctors, nurses, community health workers. The aim of the study is to assess the areas in which problems are encountered by the health care providers during delivery of DOTS therapy and hence are halting the success of DOTS and propagating the disease.

\section{Materials and Methods}

This was a cross sectional study conducted between April 2016 to Sept 2016 at Primary Health Care centers in Karachi. A convenient sampling technique was used and a verbal consent was taken from all participants. A total of 100 Health care providers were part of this study. Out of these 100 health care workers, 25 were excluded from the study due to the incomplete filling of the questionnaire. A questionnaire was filled by the workers in which Demographic, clinical and treatment outcome factors and social determinants of health were recorded for each patient. Doctors, Nurses and Health Workers working as part time at Primary Health Care centers of Karachi with experience of more than 06 months were included. The Doctors, Nurses and Health Workers working as full time at Primary Health Care center with experience of less than 06 months were excluded. Ethical considerations were followed and names of participants and care centers were kept confidential.

\section{Data Analysis}

The data was analyzed through SPSS version 17.0. The quantitative variables were expressed as mean and standard deviation and qualitative variables were expressed in form of Pie and Bar charts with frequency tables.

\section{Results}

Total 100 questionnaires were circulated out of which 75 were completely filled and were according to the inclusion criteria. Therefore, 75 were enrolled in the study and analyzed. Among the 75 respondents male to female ratio was 1:1. Around 36 (48\%) were doctors, 18 (24\%) were nurses, 21 (28\%) were lady health workers. Their working experience was less than 1 year, 1 to 5 years, 6 to 10 years and more than 10 years in 17 (22.7\%), 32 (42.7\%), $13(17.3 \%)$ and $13(17.3 \%)$ respectively.
$41(54 \%)$ out of them were found to be working in primary health care center. 32(43\%) were serving in community center and 2 (3\%) were providing care at patients home (Figure 1).

\section{Venue of Administration}

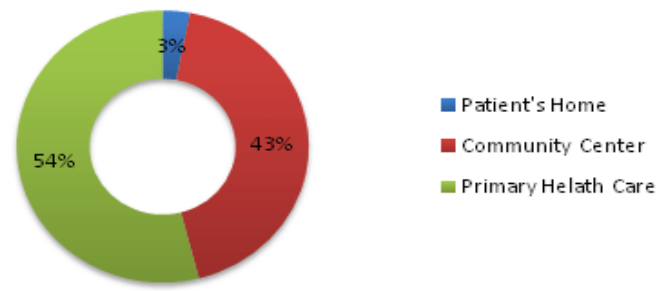

Figure 1:

The Financial support for DOTS program was stated to be adequate by $72(96 \%)$ health workers while remaining $3(4 \%)$ stated it to be inadequate for them to carry TB DOTS program. According to $72(96 \%)$ health workers appropriate material for educating ТB patient were available whereas $3(4 \%)$ health workers stated it to be insufficient. 26 health workers $(27 \%)$ reported that they faced some problem with logistics and supply of drugs while remaining 49 health workers (73\%) reported as having enough supply of logistic and drugs. Out of all health workers, 24(32\%) documented shortage of multi sectorial support but $51(68 \%)$ reported that it was appropriate. A remarkably high number of health workers reported lack of health education about TB and Primary Health Care center that hindered them in providing DOTS therapy to the patient comprising $60(80 \%)$ health workers while few15 (20\%) had to face no such issues in rendering care on basis of DOTS therapy to patients (Table 1).

\begin{tabular}{|c|c|c|c|c|}
\hline \multirow[t]{2}{*}{ Question } & \multicolumn{2}{|c|}{ Yes } & \multicolumn{2}{|c|}{ No } \\
\hline & Frequency & Percent & Frequency & Percent \\
\hline $\begin{array}{l}\text { Financial support for TB } \\
\text { DOTS Program }\end{array}$ & 72 & 96 & 3 & 4 \\
\hline $\begin{array}{l}\text { Appropriate material for } \\
\text { educating TB patient }\end{array}$ & 72 & 96 & 3 & 4 \\
\hline $\begin{array}{c}\text { Enough supply of drugs / } \\
\text { logistics }\end{array}$ & 49 & 65 & 26 & 35 \\
\hline $\begin{array}{c}\text { Multi sectorial support } \\
\text { provided }\end{array}$ & 51 & 68 & 24 & 32 \\
\hline $\begin{array}{c}\text { Health education about TB } \\
\text { and PHC }\end{array}$ & 15 & 20 & 60 & 80 \\
\hline Improve access to transport & 54 & 72 & 21 & 28 \\
\hline $\begin{array}{l}\text { Face any problem during } \\
\text { field work }\end{array}$ & 12 & 16 & 63 & 84 \\
\hline $\begin{array}{l}\text { Problem faced during } \\
\text { reporting }\end{array}$ & 13 & 17 & 62 & 83 \\
\hline Reporting tool provided & 72 & 96 & 3 & 4 \\
\hline Salary appropriate & 56 & 74 & 19 & 26 \\
\hline $\begin{array}{l}\text { Even distribution of work is } \\
\text { maintain }\end{array}$ & 71 & 95 & 4 & 5 \\
\hline Empower to voice problems & 71 & 95 & 4 & 5 \\
\hline
\end{tabular}


According to $21(28 \%)$ health workers by improving the access to transportation the implication of DOTS can be enhanced. $63(84 \%)$ of the health workers stated that they faced problems during field work that hindered them in providing DOTS therapy at initial stages of disease. A considerable number reported that they faced problem during reporting of the disease. 13(17\%) health workers had problem reporting the disease while 62(83\%) reported it with convenience. Reporting tools were available conveniently to $72(96 \%)$ health workers, only $3(4 \%)$ stated lack of reporting tool as a problem in providing adequate care. $56(74 \%)$ of the workers were satisfied with salary package and $19(26 \%)$ were not. As stated by $71(96 \%)$ health workers there was even distribution of work and empower to voice problems while remaining $4(5 \%)$ health workers documented it to be vice versa (Table 1).

A reasonable number of response obtained from the participants stated that the patient compliance was a major factor in delay or discontinuation of DOTS therapy as compared to few stating it to be average or good. The documenting frequency was below average, average and good in 46(61.3\%), 22(29.3\%), $7(9.3 \%)$ respectively (Figure 2$)$.

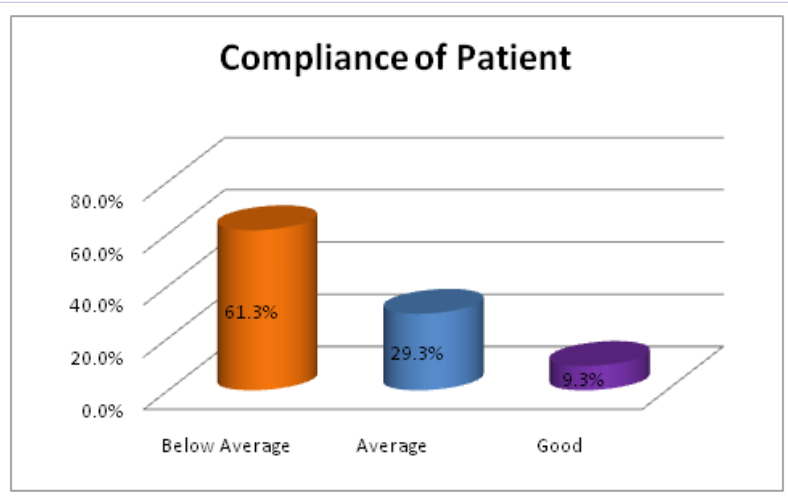

Figure 2

The overall TB DOT program was rated as Fair in $34(45 \%)$, good in 33(44\%) and very good in 8(11\%) (Figure 3).

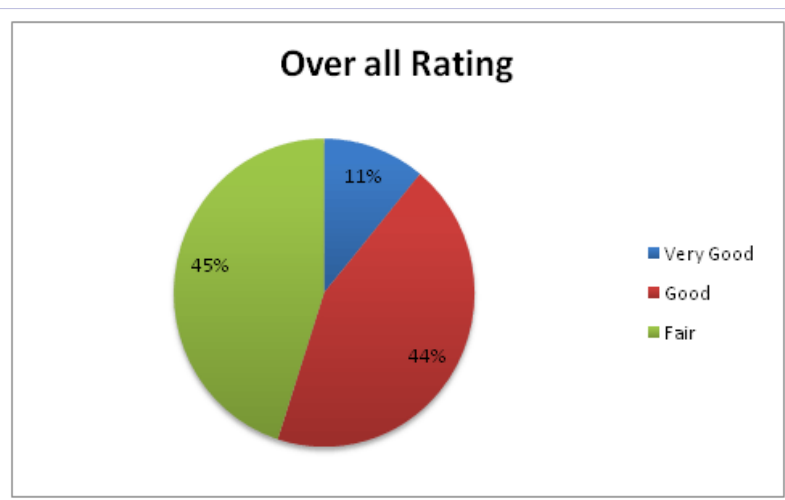

Figure 3

\section{Discussion}

Tuberculosis is one the major global health problem faced by developing countries. There has been extensive debate and dialogue on the role of DOTS in controlling the TB in future at global platforms [8].

Compliance to DOTS therapy is one of the important factors that affect the outcome of therapy. Self administration show high levels of Non compliance leading to emergence of drug resistance, increasing the expense and duration of therapy [9].

One study revealed that $73.1 \%$ patients completed TB treatment for 9 months while $28.9 \%$ failed to complete their regimen [10].

Our study also presented remarkably high number of patients being non-compliant $46(61 \%)$, hence having risk of becoming multi drug resistant and falling into TB fatal complications.

Another research conducted in Iran stated that the major factor in failure of TB DOTS strategy is non-compliance and recommendations included better follow-up for patients with diseases and enabling access to treatment can help improve implementation of DOTS, especially for Turkoman patients. A study conducted in Nigeria showed that proximity was the only important factor that had significant impact on rate of compliance during treatment $[11,12]$.

While, our study showed improved transport access in $54(72 \%)$ of health care workers and reducing the overall burden of the disease in community and increasing the compliance.

The study by Sisay et al. revealed that there were more gaps in organizational issues such as misuse and under use of TB registration book, challenges in follow-up of TB patients, low case detection of TB and increased rate of treatment defaulter [13].

Our study also highlighted the fact that support and coordination from various sectors of public health and law makers is of pivotal importance in carrying the DOTS program forward and $24(32 \%)$ indicated the lack of multi sectorial support.

The former study An Operations Research on TB Control Program in the Public Health Sector in Sindh states that the public health care system in Pakistan lacks even the basic requirements for an effective TB control program, that is, a viable information system and the functional integration of program with rest of the health care delivery system [14].

Increasing financial burden made patients prone to discontinue treatment in later stages. The patients who did not manage to restore their health and social status, had greater vulnerability to non-adherence. TB consultation and treatment increased exponentially following a monetary help by NGOs by extending free TB treatment in Nigeria [15].

Our study emphasized the importance of provision with logistics and supplies of drug can accommodate more TB patients to Health care center and improve treatment outcome. 
Drug toxicity was observed as major while feeling better during treatment and lack of knowledge were minor causes of blockade in DOTS therapy [10].

Forgetfulness, having symptoms of tuberculosis during the interview, and co-infected with HIV led to non-adherence to anti-tuberculosis therapy [16].

One of the study indicated that inaccessibility to DOTS locally lead to failure in completion of full medical treatment course. Therefore, In order to achieve high level of adherence, access to TB treatment is the core aspect. In another study the predictors of treatment failure were reported to be noncompliance to treatment and deficient patient knowledge/ health education [5]. Alternative study by Morsy et al. was in agreement to the analogous concept who reported that the possible significant risk factors for treatment failure were scarce health education sessions to the patient, poor patient knowledge regarding the disease and missed doses of Anti-Tuberculosis drugs that leaded to 11,5 and 1.4 -folds increased risk for treatment failure respectively $[17,18]$.

In our study a remarkably high number 60 (80\%) documented the lack of health education about TB.

Afghanistan, Pakistan, India, Brazil, Zimbabwe, S. Africa and Uganda are some of the countries still facing challenges in the effective introduction, implementation and expansion of DOTS. Financial inabilities contribute greatly to the failure of respective national TB control programs [19].

Previously-treated pulmonary TB had less success rate than new cases. Culture and susceptibility for previously treated group were recommended before starting treatment. Treatment at TB clinic improved treatment outcomes [20].

It is of utmost significance to treat $\mathrm{TB}$ at its first occurrence as this can help reduce the disease rate and have more successful outcomes as compared to re treating patients who discontinued their regimen.

The assets of this study are that, the multicenter approach has certified that we have appraised the accounts of extensive range of health care workers and their proficiencies to evaluate the problems faced during DOTS program. However, there are some confounders found in this study such as observer and recall bias. Considering the views of health care workers and experience and to what range they are constant with the opinions of the doctors, nurses and lady health workers would be revealing and beneficial to regulate more realities about the DOTS program. Thus, a modified combination in which the weaknesses of the DOTS program are addressed and removed will signify a composed methodology to improve its implementation.

\section{Conclusion}

There are difficulties confronted by health care providers in extending care to TB patients by DOTS therapy despite the program being in function since many years. The major areas of constrain highlighted are patient compliance to treatment, access to health facilities, education about TB and its treatment and problems faced during field work and reporting. However, refining these parameters will lead to paramount implementation of DOTS therapy and thus, can improve many folds and disease can drop reciprocally.

\section{References}

1. Esmael A, Ali I, Agonafir M, Desale A, Yaregal Z, Desta K. Assessment of Patients' Knowledge, Attitude and Practice Regarding Pulmonary Tuberculosis in Eastern Amhara Regional State, Ethiopia: CrossSectional Study. Am J Trop Med Hyg. 2013;88(4):785-788. doi: 10.4269/ajtmh.12-0312

2. Fauci AS, NIAID Tuberculosis Working Group. Multidrug-resistant and extensively drug-resistant tuberculosis: the National Institute of Allergy and Infectious Diseases Research agenda and recommendations for priority research. J Infect Dis. 2008;197(11):1493-1498. doi: $10.1086 / 587904$

3. Gebrezgabiher G, Romha G, Ejeta E, Asebe G, Zemene E, Ameni G. Treatment Outcome of Tuberculosis Patients under Directly Observed Treatment Short Course and Factors Affecting Outcome in Southern Ethiopia: A Five-Year Retrospective Study. PloS one. 2016;11(2):e0150560. doi: 10.1371/journal.pone.0150560

4. Cox HS, Morrow M, Deutschmann PW. Long term efficacy of DOTS regimens for tuberculosis: systematic review. BMJ. 2008;336(7642):484-487. doi: 10.1136/bmj.39463.640787

5. Elkomy H, Awad M, El-Shora A, Elsherbeni B. Assessment of the efficacy of Directly Observed Treatment with short course (DOTS) for pulmonary tuberculosis in Sharkia governorate. Egyptian Journal of Chest Diseases and Tuberculosis. 2013;62(2):257-261

6. Khan WM, Smith H, Qadeer E, Hassounah S. Knowledge and perceptions of national and provincial tuberculosis control programme managers in Pakistan about the WHO Stop TB strategy: a qualitative study. JRSM Open. 2016;8(1):2054270416675084 doi: $10.1177 / 2054270416675084$

7. Otu AA. Is the directly observed therapy short course (DOTS) an effective strategy for tuberculosis control in a developing country?. Asian Pac J Trop Dis. 2013;3(3):227-231 doi: 10.1016/S22221808(13)60045-6

8. Raviglione MC, Pio A. Evolution of WHO policies for tuberculosis control, 1948-2001. The Lancet. 2002;359(9308):775-780

19. Chaudhry LA, Al-Tawfiq J, Ba-Essa E, Robert AA. Low rate of noncompliance to antituberculous therapy under the banner of directly observed treatment short course (DOTS) strategy and well organized retrieval system: a call for implementation of this strategy at all DOTS centers in Saudi Arabia. Pan Afr Med J. 2015;21(1):267 doi: 10.11604/ pamj.2015.21.267.6280

10. Ibrahim KM, Khan S, Laaser U. Tuberculosis control: current status, challenges and barriers ahead in 22 high endemic countries. Journal of Ayub Medical College, Abbottabad: JAMC . 2002;14(4):11-15

11. Mohammadzadeh KA, Ghayoomi A, Maghsoudloo D. Evaluation of factors associated with failure of tuberculosis treatment under DOTS in northern Islamic Republic of Iran. Eastern Mediterranean Health Journal. 2016;22(2):87

12. Pritchard AJ, Hayward AC, Monk PN, Neal KR. Risk factors for drug resistant tuberculosis in Leicestershire-poor adherence to treatment remains an important cause of resistance. Epidemiol Infect. 2003;130(03):481-483 


\section{Encountered}

13. Sisay S, Mengistu B, Erku W, Woldeyohannes D. Directly Observed Treatment Short-course (DOTS) for tuberculosis control program in Gambella Regional State, Ethiopia: ten years experience. BMC Res Notes. 2014;7:44 doi: 10.1186/1756-0500-7-44

14. Israr SM. Is Ministry of Health fully prepared to implement an effective DOTS program in Pakistan? An Operations Research on TB Control Program in the Public Health Sector in Sindh. J Pak Med Assoc. 2003;53(8):324-327

15. Awofeso N, Schelokova I, Dalhatu A. Training of front-line health workers for tuberculosis control: Lessons from Nigeria and Kyrgyzstan. Hum Resour Health. 2008;6(1):20. doi: 10.1186/1478-4491-6-20

16. Adane AA, Alene KA, Koye DN, Zeleke BM. Non-adherence to antituberculosis treatment and determinant factors among patients with tuberculosis in northwest Ethiopia. PloS one. 2013;8(11):e78791. doi:10.1371/journal.pone.0078791

17. Ukwaja KN, Alobu I, Onu EM. Frontline healthcare workers' knowledge of tuberculosis in rural south-east Nigeria. Afr J Respir Med. 2013;9(1):7-10

18. Morsy AM, Zaher HH, Hassan MH, Shouman A. Predictors of treatment failure among tuberculosis patients under DOTS strategy in Egypt:national tuberculosis control programme, Ministry of Health and Population, Cairo, Egypt. East Mediterr Health J. 2003;9(4):689701

19. Mauch V, Weil D, Munim A, Boillot F, Coninx R, Huseynova S, et al Structure and management of tuberculosis control programs in fragile states-Afghanistan, DR Congo, Haiti, Somalia. Health Policy. 2010;96(2):118-127

20. Reechaipichitkul W, So-Ngern A, Chaimanee P. Treatment Outcomes of New and Previously-Treated Smear Positive Pulmonary Tuberculosis at Srinagarind Hospital, a Tertiary Care Center in Northeast Thailand. J Med Assoc Thai. 2014;97(5):490-499 